\title{
Method for calculating strength, crack resistance and stiffness of reinforced concrete beams reinforced with steel fiber concrete based on a nonlinear deformation model
}

\author{
Oleg Radaykin ${ }^{1, *}$, and Linar Sharafutdinov ${ }^{2}$ \\ ${ }^{1}$ Kazan State Power Engineering University, 420066, Kazan, Russia \\ ${ }^{2}$ Kazan State University of Architecture and Civil Engineering, 420043, Kazan, Russia
}

\begin{abstract}
A very promising way of strengthening reinforced concrete beams looks to be the use of a "jacket" made of steel fiber reinforced concrete for these purposes. There are two good reasons for this: first, in terms of the manufacturing laboriousness, the device of such a "jacket" is comparable to the application of ordinary plaster, and, second, the observed increase in the reinforced beams' bearing capacity is quite comparable with the use of a steel clip. The literature analysis has shown that the methods for calculating the considered reinforcement method, which would take into account the features of steel fiber concrete as a material, as well as the features of the joint work of the "jacket" with the reinforced beam, does not yet exist. To obtain such a technique, the most suitable, in our opinion, is a numerical diagrammatic method based on the so-called nonlinear deformation model. With its use, a detailed algorithm for calculating the strength, crack resistance and stiffness of reinforced beams has been developed in this article. Comparison of the calculation results with their own experimental data and other authors, the difference in the moment of destruction was $16.46 \%$, for the moment of cracking $9.2 \%$, which indicates the proposed method's efficiency.
\end{abstract}

\section{Introduction}

A very promising way of reinforcing reinforced concrete structures looks like the use of a "jacket" made of steel fiber reinforced concrete (FRC). There are two good reasons for this: first, in terms of the manufacturing laboriousness, the device of such a "jacket" is comparable to the application of ordinary plaster, and, second, the observed increase in the reinforced beams' bearing capacity is quite comparable with the use of a steel clip.

In the normative literature on the design of strengthened concrete structures' reinforcement in particular in [BC 349.1325800], the calculation of such structures is based on the method of limiting the forces set forth in [BC 63.13330], with the introduction of an additional working condition factor that takes into account the insufficient unloading of the structure at the reinforcement moment, which for concrete and reinforcement is 0.9

*Corresponding author: olegxxii@mail.ru 
$\left(\gamma_{b r l}=\gamma_{s r l}=0.9\right)$. In the general case, it is recommended to perform the analysis of structures containing concrete and reinforcement of several classes simultaneously using a nonlinear deformation model in accordance with BC 63.13330, taking the coefficients $\gamma_{b r l}, \gamma_{s r l}$, as well as the initial stress state of the structure before reinforcement into account. At the same time, no algorithm is given on how to do this, including how to take into consideration the creep and shrinkage of concrete, the adhesion of new and old concrete.

In the framework of scientific research [1-3] for the eccentrically compressed elements reinforced with a reinforced concrete cage, the attempts to take into account the prehistory of loading and nonlinear properties of concrete were made. For the bending elements, such studies were not found.

The monograph [4] takes into account the initial state of the beams preceding the reinforcement. However, the given dependencies refer to reinforcement by build-up in compressed and / or stretched zones of the section, and "jackets" are not considered. The contribution to the structure under load operation of a one- or two-sided reinforced element, as shown by experimental and numerical data [5-8], differs significantly from reinforcement from three sides by a "jacket". In addition, ordinary reinforced concrete is used as the reinforcement material in [4], rather than FRC.

The works $[9,10]$ can be distinguished of the FRC calculation methods found in the literature, used to create "jackets". However, here the "jacket" plays the role of a permanent formwork, and the operational stage calculation is based on the methodology [BC 52-1012003] with replacement of the bar reinforcement characteristics with the characteristics of steel fiber concrete.

In connection with the above-said, the goal of this work was to develop, in the first approximation, a method for calculating the strength, crack resistance and stiffness of reinforced concrete beams reinforced with a "jacket" made of steel fiber reinforced concrete, based on a nonlinear deformation model [BC 63.13330] with a short load.

\section{Models and methods}

Calculation of strength and crack resistance of a reinforced concrete element is based on the general provisions for the nonlinear deformation model [BC 63.13330], taking into account the algorithms and deformation diagrams given in [11], using the material diagrams proposed in [12-16]. The algorithm is implemented in computer software MathCAD 14.0.

\section{Calculation algorithms}

The design diagram of a reinforced bending reinforced concrete element section is shown in Fig. 1. The calculation algorithm is shown in Table 1. According to the technique, the section is considered as a set of elementary layers with uniformly distributed deformations and stresses on each layer. Along with this, the hypothesis of flat sections for the section average longitudinal deformations is applied. 


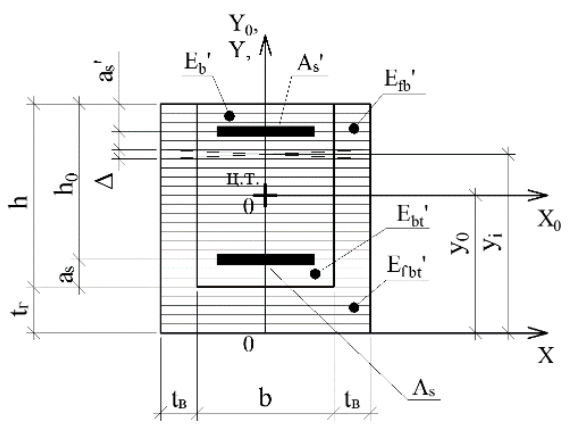

Fig. 1. Design diagram of the cross-section of a bent strengthened concrete element reinforced with a steel-fiber-concrete jacket for constructing a nonlinear deformed model

Table 1. Algorithm for calculating the strength, crack resistance, stiffness of the normal section of a strengthened concrete element reinforced with a "jacket"

\begin{tabular}{|c|c|c|}
\hline No. & Stage description & Basic design expressions and quantities \\
\hline & \multirow{2}{*}{\multicolumn{2}{|c|}{$\begin{array}{l}\text { Initial data } \\
\text { Design scheme, beam span } L \text {, span of cut a; cross-section of a reinforced beam b, h; } \\
\text { area of stretched and compressed reinforcement } A_{s}, A_{s}^{\prime} ; \text {; binding of tensioned and } \\
\text { compressed reinforcement to the nearest concrete faces } a_{s}, a_{s}^{\prime} ; \text { thickness of steel fiber } \\
\text { reinforced concrete jacket - horizontal and vertical parts }-t_{t}, t_{2} ; \text { jacket reinforcement } \\
\text { length } l_{f} \text {, percentage of fiber reinforcement by volume } \mu_{f v} ; \text { concrete class of the beam } B \text {, } \\
\text { concrete density } \rho \text {; steel fiber concrete class } B_{f}, B_{f t}, B_{f t} \text {, density of steel fiber concrete } \\
\rho_{f} \text {, type of fiber; reinforcement class } A \text {; type of deformation diagrams of concrete, } \\
\text { reinforcement and steel fiber reinforced concrete; design load } P \text {, normative load } P_{n} \text {. }\end{array}$}} \\
\hline 1. & & \\
\hline \multicolumn{3}{|c|}{ Stage I - Determination of forces in the section } \\
\hline 2. & $\begin{array}{l}\text { In the design section, } \\
\text { according to the } \\
\text { formulas of structural } \\
\text { mechanics and } \\
\text { resistance of materials, } \\
\text { the bending moment } \\
\text { arising from the action } \\
\text { of design and standard } \\
\text { loads is determined. }\end{array}$ & $\begin{array}{c}\quad M=P \cdot \frac{a}{2}+\frac{\gamma_{f} b h \rho L^{2}}{2}+\frac{\gamma_{f}\left[b t_{c}+2 t_{b}\left(h+t_{z}\right)\right] \rho_{f} L^{2}}{2} \\
M_{n}=P_{n} \cdot \frac{a}{2}+\frac{b h \rho L^{2}}{2}+\frac{\left[b t_{c}+2 t_{b}\left(h+t_{c}\right)\right] \rho_{f} L^{2}}{2} \\
\text { (for a four-point bend, taking into account its own weight) }\end{array}$ \\
\hline & \multicolumn{2}{|r|}{ Stage II - First approximation } \\
\hline 3. & $\begin{array}{l}\text { The initial } \\
\text { approximation of the } \\
\text { required parameter is } \\
\text { set: the limiting } \\
\text { moment, the moment of } \\
\text { cracking. To do this, the } \\
\text { approximate formulas of } \\
\text { the method of limiting } \\
\text { efforts is used. }\end{array}$ & $\begin{array}{c}M_{u l t}=R_{b}\left(b+2 t_{6}\right) \frac{h_{0}}{3}\left(h_{0}-0,5 \frac{h_{0}}{3}\right) \\
M_{c r c, f b}=1,75 R_{f b t n} \cdot \frac{b\left(h+t_{z}\right)^{2}}{6}\end{array}$ \\
\hline 4. & $\begin{array}{c}\text { The starting position of } \\
\text { the neutral axis is } \\
\text { determined }\end{array}$ & $y_{0}=\frac{h+t_{2}}{2}$ \\
\hline 5. & $\begin{array}{l}\text { The initial value of the } \\
\text { flexural stiffness is } \\
\text { calculated }\end{array}$ & $B_{x}=E_{b} \frac{b\left(h+t_{2}\right)^{3}}{12}$ \\
\hline 6. & $\begin{array}{l}\text { Calculate the initial } \\
\text { value of the curvature }\end{array}$ & $\left(\frac{1}{r}\right)_{u l t} \approx \frac{M_{u l t}}{B_{x}}\left(\frac{1}{r}\right)_{c r c} \approx \frac{M_{c r c}}{B_{x}} \frac{1}{r} \approx \frac{M_{n}}{B_{x}}$ \\
\hline
\end{tabular}




\begin{tabular}{|c|c|c|}
\hline No. & Stage description & Basic design expressions and quantities \\
\hline 7. & $\begin{array}{l}\text { For a given strength } \\
\text { class of concrete, steel } \\
\text { fiber concrete and } \\
\text { reinforcement and the } \\
\text { corresponding strength } \\
\text { and deformation } \\
\text { characteristics of } \\
\text { materials } \\
\text { calculation and } \\
\text { normative diagrams are } \\
\text { built } \\
\text { deformation: for } \\
\text { reinforcement - two-line } \\
\text { Prandtl or three-line, for } \\
\text { concrete, steel-fiber } \\
\text { reinforced concrete - } \\
\text { two-line or curved [12, } \\
16]\end{array}$ & $\left\langle\sigma_{b}-\varepsilon b\right\rangle,,\left\langle\sigma_{b t}-\varepsilon b t\right\rangle,\left\langle\sigma_{s}-\varepsilon_{s}\right\rangle,\left\langle\sigma_{s c}-\varepsilon_{s c}\right\rangle,\left\langle\sigma_{f b}-\varepsilon f b\right\rangle,\left\langle\sigma_{f b t}-\varepsilon_{f f b t}\right\rangle$ \\
\hline 8. & $\begin{array}{l}\text { The position of the } \\
\text { coordinate } \\
\text { axes Oxy is set- it is } \\
\text { recommended to } \\
\text { combine them with the } \\
\text { axes of symmetry of the } \\
\text { section or the faces of } \\
\text { the concrete section. } \\
\text { The section is divided in } \\
\text { height into strips ( } n \geq 10 \text { ), } \\
\text { an integer number of } \\
\text { subdivisions for the } \\
\text { thickness of the jacket is } \\
\text { determined. For each } \\
\text { strip, we determine its } \\
\text { coordinate yi make up } \\
\text { a calculation scheme. }\end{array}$ & $n, \Delta=\left(h+t_{2}\right) / n, y_{i}=\Delta(i+0.5), i \in[1, n-1]$ \\
\hline 9. & $\begin{array}{c}\text { Set by the number of } \\
\text { iterations, not less than } \\
20\end{array}$ & $m \geq 20$ \\
\hline \multicolumn{3}{|c|}{ Stage III - Iterative process } \\
\hline 10. & $\begin{array}{l}\text { Using the hypothesis of } \\
\text { flat sections, the relative } \\
\text { deformations in } \\
\text { concrete, steel-fiber- } \\
\text { reinforced concrete and } \\
\text { reinforcement are } \\
\text { calculated }\end{array}$ & $\begin{aligned} & \text { for strength calculation, } M_{u l t}: \\
& \varepsilon_{i}=\left(\frac{1}{r}\right)_{u l t}\left(y_{0}-y_{i}\right) \\
& \varepsilon_{s}=\left(\frac{1}{r}\right)_{u l t}\left(y_{0}-\left(a_{s}+t_{2}\right)\right) \\
& \varepsilon_{s c}=\left(\frac{1}{r}\right)_{u l t}\left(h+t_{2}-y_{0}-a_{s}^{\prime}\right) \\
& \text { for calculating the moment of crack formation, } M_{c r c} \text { : }=\left(\frac{1}{r}\right)_{c r c}\left(y_{0}-y_{i}\right) \\
& \varepsilon_{s}=\left(\frac{1}{r}\right)_{c r c}\left(y_{0}-\left(a_{s}+t_{2}\right)\right) \\
& \varepsilon_{s c}=\left(\frac{1}{r}\right)_{c r c}\left(h+t_{2}-y_{0}-a_{s}^{\prime}\right) \\
& \text { for deflection calculation. f: }\end{aligned}$ \\
\hline
\end{tabular}




\begin{tabular}{|c|c|c|}
\hline No. & Stage description & Basic design expressions and quantities \\
\hline & & $\begin{array}{c}\varepsilon_{i}=\frac{1}{r}\left(y_{0}-y_{i}\right) \\
\varepsilon_{s}=\frac{1}{r}\left(y_{0}-\left(a_{s}+t_{2}\right)\right) \\
\varepsilon_{s c}=\frac{1}{r}\left(h+t_{2}-y_{0}-a_{s}^{\prime}\right) \\
\text { where } \varepsilon_{i} \text { defines deformations in steel fiber concrete and } \\
\text { concrete, } \begin{array}{c}\varepsilon_{s}, \varepsilon_{s c} \text { show the deformations in tensile and } \\
\text { compressed reinforcement }\end{array}\end{array}$ \\
\hline 11. & 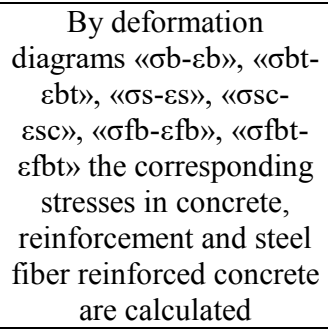 & $\sigma_{b}, \sigma_{b t}, \sigma_{s,}, \sigma_{s c}, \sigma_{f b}, \sigma_{f b t}$ \\
\hline 12. & $\begin{array}{l}\text { The deformations and } \\
\text { stresses in tensile } \\
\text { reinforcement at the } \\
\text { time of crack initiation } \\
\text { are determined }\end{array}$ & $\begin{array}{c}\varepsilon_{s, c r c}=\frac{\varepsilon_{b t 2}\left(y_{0}-a_{s}\right)}{y_{0}}, \sigma_{s, c r c}=E_{s} \varepsilon_{s, c r c} \\
\text { (for strength calculations only, } M_{u l t} \text {, and deflection, } f \text { ) }\end{array}$ \\
\hline 13. & $\begin{array}{l}\text { A coefficient that takes } \\
\text { into account the joint } \\
\text { work of tensile concrete } \\
\text { and reinforcement in the } \\
\text { area between the cracks } \\
\text { is determined. }\end{array}$ & $\begin{array}{c}\psi_{s}=1-0,8 \frac{\sigma_{s, c r c}}{\sigma_{s}} \\
\sigma_{s, c r c} \text { shows stresses in tensile reinforcement at the moment } \\
\text { of crack initiation } \\
\text { (for strength calculations only, } M_{u l t} \text {, and deflection, } f \text { ) }\end{array}$ \\
\hline 14. & $\begin{array}{l}\text { Secant modules of } \\
\text { concrete, reinforcement } \\
\text { and FRC are calculated }\end{array}$ & $E_{b, i}^{\mathrm{sec}}=\frac{\sigma_{b, i}}{\varepsilon_{b, i}}, E_{s}^{\mathrm{sec}}=\frac{\sigma_{s}}{\psi_{s} \varepsilon_{s}}, E_{s c}^{\mathrm{sec}}=\frac{\sigma_{s c}}{\varepsilon_{s c}}, E_{f b, i}^{\mathrm{sec}}=\frac{\sigma_{f b, i}}{\varepsilon_{f b, i}}$ \\
\hline 15. & $\begin{array}{l}\text { The position of the } \\
\text { neutral axis is clarified }\end{array}$ & 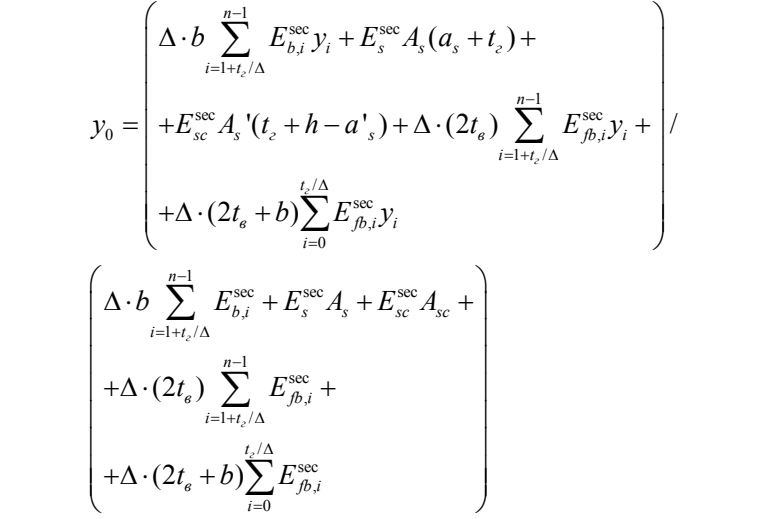 \\
\hline 16. & $\begin{array}{l}\text { The bending stiffness of } \\
\text { the section is refined }\end{array}$ & $\begin{array}{l}B_{x}=\Delta \cdot b \sum_{i=1+t_{2} / \Delta}^{n-1} E_{b, i}^{\mathrm{sec}}\left(y_{0}-y_{i}\right)^{2}+ \\
+E_{s}^{\mathrm{sec}} A_{s}\left(y_{0}-\left(a_{s}+t_{2}\right)\right)^{2}+E_{s c}^{\mathrm{sec}} A_{s}{ }^{\prime}\left(y_{0}-\left(t_{2}+h-a_{s}^{\prime}\right)\right)^{2}+ \\
+\Delta \cdot\left(2 t_{\sigma}\right) \sum_{i=1+t_{2} / \Delta}^{n-1} E_{f b, i}^{\mathrm{sec}}\left(y_{0}-y_{i}\right)^{2}+\Delta \cdot\left(2 t_{\sigma}+b\right) \sum_{i=0}^{t, \Delta} E_{f b, i}^{\mathrm{sec}}\left(y_{0}-y_{i}\right)^{2}\end{array}$ \\
\hline 17. & $\begin{array}{l}\text { The curvature is } \\
\text { clarified }\end{array}$ & for strength calculation, $M_{u l t}$ : \\
\hline
\end{tabular}




\begin{tabular}{|c|c|c|}
\hline No. & Stage description & Basic design expressions and quantities \\
\hline & & $\begin{array}{l}\left(\frac{1}{r}\right)_{\text {ult }}=\min \left[\frac{\varepsilon_{b 2}}{h-y_{0}}, \frac{\varepsilon_{s c 0}}{h+t_{2}-a_{s}^{\prime}-y_{0}}, \frac{\varepsilon_{s 0}}{y_{0}-t_{2}-a_{s}}\right] \\
\text { for calculating the moment of cracking, } M_{c r c} \text { : } \\
\qquad\left(\frac{1}{r}\right)_{c r c}=\frac{\varepsilon_{f b t 2}}{y_{0}} \\
\text { for deflection calculation, } f: \\
\frac{1}{r}=\frac{M_{n}}{B_{x}}\end{array}$ \\
\hline 18. & $\begin{array}{l}\text { If the difference in } \\
\text { curvatures obtained at } \\
\text { this and the previous } \\
\text { iteration exceeds } 0,5 \% \text {, } \\
\text { then the calculation is } \\
\text { repeated with p. } 10\end{array}$ & {$\left[\frac{1}{r}-\frac{1^{\prime}}{r}\right] / \frac{1}{r}<0,005$} \\
\hline 19. & $\begin{array}{l}\text { The final values of } \\
\text { strength and fracture } \\
\text { toughness are } \\
\text { determined including } \\
\text { crack opening width, } \\
\text { deflections }\end{array}$ & $\begin{array}{c}M_{u l t}=\left(\frac{1}{r}\right)_{u l t} B_{x}, M_{c r c}=\left(\frac{1}{r}\right)_{c r c} B_{x}, a_{c r c}=\varphi_{1} \varphi_{2} \varphi_{3} \frac{\sigma_{s}}{E_{s, r e d}^{\text {sec }}} l_{s} \\
f=S \frac{1}{r} l^{2}\end{array}$ \\
\hline 20. & $\begin{array}{l}\text { Output of intermediate } \\
\text { results for analysis }\end{array}$ & $\begin{array}{l}B_{x},\left(\frac{1}{r}\right)_{u l t},\left(\frac{1}{r}\right)_{c r c}, \frac{1}{r} \\
\varepsilon_{b}, \varepsilon_{b t}, \varepsilon_{f b}, \varepsilon_{f b t}, \varepsilon_{s}, \varepsilon_{s c}, \sigma_{b}, \sigma_{b t}, \sigma_{f b}, \sigma_{f b t}, \sigma_{s}, \sigma_{s c}\end{array}$ \\
\hline \multicolumn{3}{|c|}{ Stage III - Verification calculations } \\
\hline 21. & $\begin{array}{l}\text { The necessary tests of } \\
\text { strength, stiffness and } \\
\text { crack resistance are } \\
\text { carried out }\end{array}$ & $M \leq M_{u l t}, M \leq M_{c r c}, f \leq f_{u l t}$ \\
\hline
\end{tabular}

To verify the presented technique, we will perform the calculation of experimental samples, the data for which are given in $[17,18]$.

\subsection{Initial data}

The section dimensions of a reinforced concrete beam $b=0.15 \mathrm{~m}, h=0.2 \mathrm{~m}$. Rebar snapping $a_{s}{ }^{\prime}=0.036 \mathrm{~m}, a_{s}=0.036 \mathrm{~m}$. Stretched and compressed reinforcement area $A_{s}=226 \cdot 10^{-6} \mathrm{~m}^{2}$, $A^{\prime}{ }_{s}=226 \cdot 10^{-6} \mathrm{~m}^{2}$. Jacket thickness vertical and horizontal $t_{v}=0.04 \mathrm{~m}, t_{g}=0.05 \mathrm{~m}$. Percentage of steel fiber reinforcement by volume $\mu_{f v}=3 \%$. Bending moment taking into account its own weight is $\mathrm{M}=20.87 \mathrm{kNm}$. Average compressive strength of concrete $30.9 \mathrm{MPa}$, average compressive strength of steel fiber concrete $137 \mathrm{MPa}$, average tensile strength of steel fiber concrete $11.5 \mathrm{MPa}$.

The curvilinear diagram of concrete [12] under tension and compression is shown in Fig. $2(a, b)$. The curvilinear diagram for steel fiber reinforced concrete is taken in tension according to $\mathrm{BC} 360.1325800$ taking into account the experimental data $[17,18]$ for compression, calculated according to [16], shown in Fig. 2 (c, d). For reinforcement, the Prandtl diagram is adopted, shown in Fig. 2 (e). 


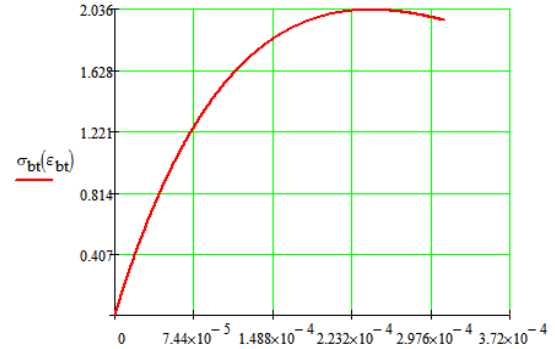

a)
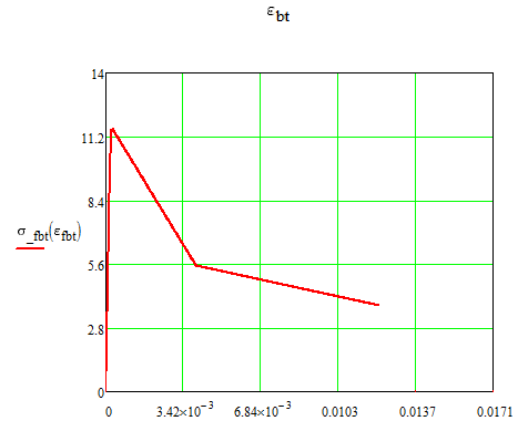

c)

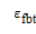

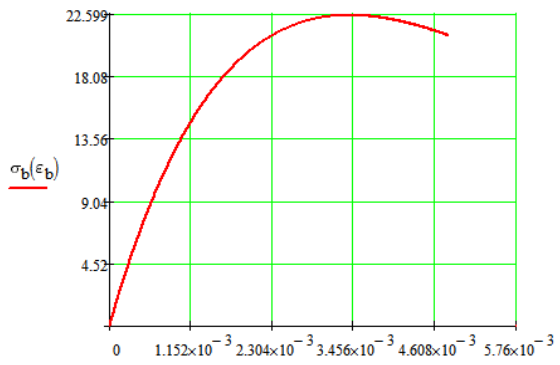

b)

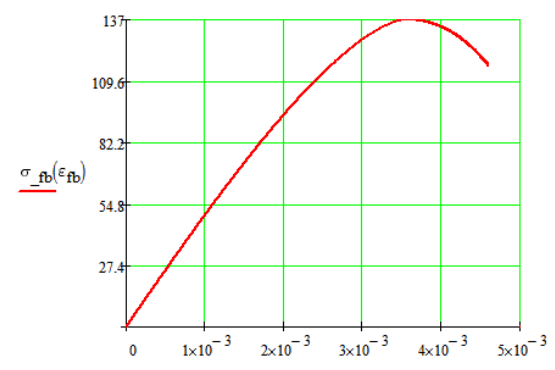

d)

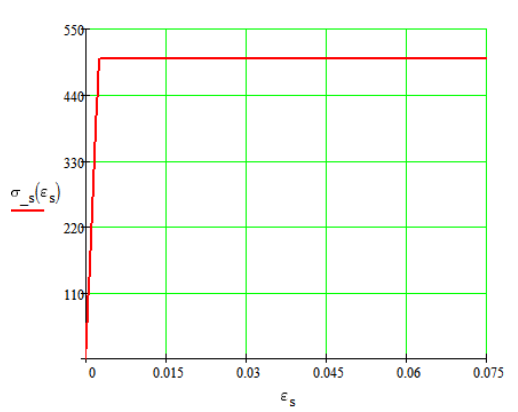

e)

Fig. 2. Deformation diagram for: a) concrete under tension, b) concrete under compression, c) steel fiber reinforced concrete under tension, d) steel fiber reinforced concrete under compression, e) reinforcement under tension.

First approximation. The initial approximation of the required parameters: the limiting moment, the moment of cracking.

$$
\begin{aligned}
& M_{u l t}=22.599 \mathrm{MPa} \cdot(0.15 \mathrm{~m}+2 \cdot 0.04 \mathrm{~m}) \frac{0.164 \mathrm{~m}}{3}\left(0.164 \mathrm{~m}-0.5 \frac{0.164 \mathrm{~m}}{3}\right)=38.834 \mathrm{kNm} \\
& M_{c r c, f b}=1.75 \cdot 11.5 \mathrm{MPa} \cdot \frac{0.15 \mathrm{~m}(0.2 \mathrm{~m}+0.05 \mathrm{~m})^{2}}{6}=31.445 \mathrm{kNm}
\end{aligned}
$$

Initial value of the neutral axis:

$$
y_{0}=\frac{0.2 m+0.05 m}{2}=0.125 m
$$

Initial value of flexural stiffness: 


$$
B_{x}=29350 M P a \frac{0.15 m \cdot(0.2 m+0.05 m)^{3}}{12}=5733 \kappa N m^{2}
$$

Curvature in the first approximation:

$$
\begin{aligned}
& \left(\frac{1}{r}\right)_{c r c, f b}=\frac{31.445 \mathrm{kNm}}{5733 \mathrm{kNm}^{2}}=5.485 \cdot 10^{-3} \mathrm{~m}^{-1} \\
& \left(\frac{1}{r}\right)_{u l t}=\frac{38.834 \mathrm{kNm}}{5733 \mathrm{kNm}^{2}}=6.774 \cdot 10^{-3} \mathrm{~m}^{-1} \\
& \frac{1}{r}=\frac{20.87 \mathrm{kNm}}{5733 \mathrm{kNm}^{2}}=3.64 \cdot 10^{-3} \mathrm{~m}^{-1}
\end{aligned}
$$

Number of sections to split the section $n=75$. The height of one strip is $\Delta=(0.200+0.05) / 75=0.00333 \mathrm{~m}$. The strip coordinates are $y_{l}=0.00333(1+0.5)=0.005 \mathrm{M}, y_{2}=$ $0.00333(2+0.5)=0.00833 \mathrm{~m}$ etc.

\subsection{Iterative process}

The iterative process for determining the moment of cracking is presented in Table 2, for the moment of fracture in Table 3, for the deflections in Table 4. As it can be seen from Tables 2, 3, 4, the optimal number of iterations is 9 , at which the difference in curvatures obtained at the last two iterations, less than $0.5 \%$.

Table 2. Iterative process for determining $M_{c r c, f b}$

\begin{tabular}{|c|c|c|c|c|c|c|c|c|c|}
\hline iteration no. & 1 & 2 & 3 & 4 & 5 & 6 & 7 & 8 & 9 \\
\hline $\begin{array}{c}M_{\text {crc.fb }} \\
\mathrm{kNm}\end{array}$ & 40.0 & 32.5 & 36.3 & 40.0 & 44.8 & 68.5 & 36.0 & 35.2 & 35.0 \\
\hline$\frac{1}{r}$ & 0.089 & 0.081 & 0.073 & 0.067 & 0.061 & 0.058 & 0.057 & 0.057 & 0.057 \\
\hline$\left[\frac{1}{r}-\left(\frac{1}{r}\right)^{\prime}\right] / \frac{1}{r}$ & 0.938 & -0.098 & -0.109 & -0.089 & -0.098 & -0.052 & -0.017 & 0 & 0 \\
\hline
\end{tabular}

Table 3. Iterative process for determining $\mathrm{M}_{\mathrm{ult}}$

\begin{tabular}{|c|c|c|c|c|c|c|c|c|c|}
\hline iteration no. & 1 & 2 & 3 & 4 & 5 & 6 & 7 & 8 & 9 \\
\hline $\begin{array}{c}M_{u l t}, \\
\mathrm{kNm}\end{array}$ & 183.7 & 62.1 & 41.2 & 40.5 & 40.5 & 40.5 & 40.5 & 40.5 & 40.5 \\
\hline$\frac{1}{r}$ & 0.029 & 0.029 & 0.025 & 0.024 & 0.024 & 0.024 & 0.024 & 0.029 & 0.029 \\
\hline$\left[\frac{1}{r}-\left(\frac{1}{r}\right)^{\prime}\right] / \frac{1}{r}$ & 0.766 & 0 & -0.16 & -0.042 & 0 & 0 & 0 & 0.766 & 0 \\
\hline
\end{tabular}

Table 4. Iterative Process for Defining Deflection $f$

\begin{tabular}{|c|c|c|c|}
\hline iteration no. & 1 & 2 & 3 \\
\hline$f, \mathrm{~mm}$ & 0.9 & 0.9 & 11 \\
\hline$\frac{1}{r} \cdot 10^{3}$ & 2.289 & 2.289 & 2.289 \\
\hline
\end{tabular}




\begin{tabular}{|l|l|l|l|}
\hline$\left[\frac{1}{r}-\left(\frac{1}{r}\right)^{\prime}\right] / \frac{1}{r}$ & -0.59 & 0 & 0 \\
\hline
\end{tabular}

To test the performance of the proposed algorithm, the experimental data [17-20] will be used. Comparison for the moment of cracking $M_{c r c, f b}$ and destruction $M_{u l t}$ is given in Table 5. Fig. 3 shows a comparison of the experimental and theoretical curves of the deflection dependence on the load.

Table 5. Comparison of calculation results with the experimental data

\begin{tabular}{|c|c|c|c|c|c|c|}
\hline & \multicolumn{3}{|c|}{$M_{\text {crc fb }}, \mathrm{kNm}$} & \multicolumn{3}{|c|}{$M_{\text {ult }} \mathrm{kNm}$} \\
\cline { 2 - 7 } & $M_{\exp }$ & $M_{\text {th }}$ & $\begin{array}{c}\left(M_{\text {th }}-M_{\exp }\right) / \\
M_{\exp } \cdot 100 \%\end{array}$ & $M_{\exp }$ & $M_{\text {th }}$ & $\begin{array}{c}\left(M_{\text {th }}-M_{\exp }\right) / \\
M_{\exp } \cdot 100 \%\end{array}$ \\
\hline $\begin{array}{c}\text { Experiment } \\
{[17,18]}\end{array}$ & 34.87 & 35.021 & $-0.433 \%$ & 48.55 & 40.558 & $+16.46 \%$ \\
\hline $\begin{array}{c}\text { Experiment } \\
{[19]}\end{array}$ & 8.27 & 8.16 & $-1.3 \%$ & 18.4 & 19.06 & $+3.58 \%$ \\
\hline $\begin{array}{c}\text { Experiment } \\
{[20]}\end{array}$ & 136.25 & 148.79 & $+9.2 \%$ & 223.45 & 221.79 & $-0.74 \%$ \\
\hline
\end{tabular}

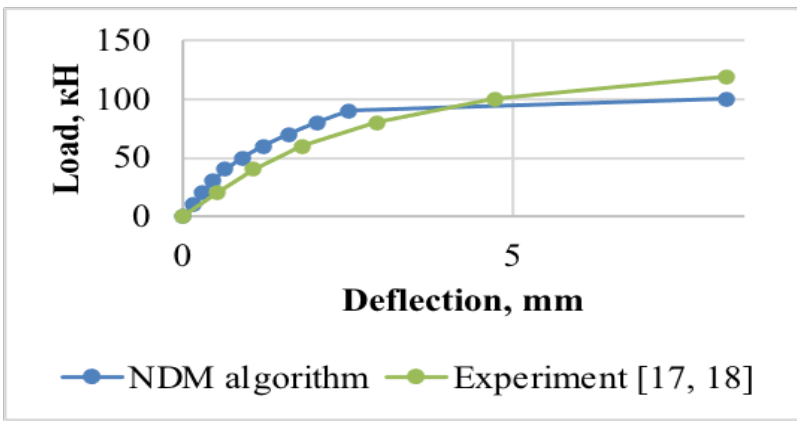

Fig. 3. Curve of deflection dependence on load according to the experimental data $[17,18]$ and according to the proposed algorithm

\section{Conclusions}

1. An algorithm for calculating the strength and crack resistance of reinforced concrete bending elements reinforced with a jacket made of steel fiber reinforced concrete using a nonlinear deformation model has been developed.

2. Comparison of the calculation results according to the proposed method with the experimental data from the works of different authors [17-20] for the samples differing in cross-sectional dimensions, reinforcement, concrete class. The difference in the results for the moment of cracking was in the range from -1.3 to $9.2 \%$, for the moment of fracture in the range from -0.74 to $16.46 \%$. For maximum deflections - within $20 \%$.

\section{References}

1. R.F. Fardiev, R.A. Kayumov, I.I. Mustafin, Izvestiya KGASU 1 (15), 109-114 (2011).

2. R.F. Fardiev, A.I. Mustafin, Integration, partnership and innovation in construction science and education.

3. R.F. Fardiev, A.I. Mustafin, Construction industry: yesterday, today, tomorrow, 2010. 
4. D.N. Lazovsky, Strengthening reinforced concrete structures of exploited building structures: monograph (PSU Publishing House, Novopolotsk, 1998).

5. R. Franssen, S. Guner, L. Courard, B. Mihaylov, MATEC Web of Conferences ICCRRR 2018199 (09001), 1-10 (2018).

6. A. Bahraq, M. Al-Osta, Sh. Ahmad, M.M. Al-Zahrani, International Journal of Concrete Structures and Materials 13 (1), 1-19 (2019).

7. K. Anusree, P. Anuragi, International Journal of Applied Engineering Research 14 (12), 10-14 (2019).

8. K. Holschemacher, Sh. Iqbal, A. Alia, Th.A. Bierb, Procedia Engineering 172, 369-376 (2017).

9. D.E. Kapustin, Scientific Review 14, 77-80 (2015).

10. D.E. Kapustin, Energetik 10, 28-36 (2015).

11. N.I. Karpenko, B.S. Sokolov, O.V. Radaikin, Design of concrete, reinforced concrete, stone and reinforced-masonry elements and structures using diagrammatic calculation methods: monograph (Publishing house ASV, Moscow, 2019).

12. O.V. Radaykin, Bulletin of civil engineers 6, 71-78 (2017).

13. N.I. Karpenko, B.S. Sokolov, O.V. Radaikin, Construction and reconstruction 2, 11-20 (2012).

14. N.I. Karpenko, O.V. Radaikin, Building and reconstruction 3 (41), 10-17 (2012).

15. N.I. Karpenko, V.I. Travush and others, Statically indeterminate reinforced concrete structures. Diagrammatic methods of computer-aided calculation and design, Federal Autonomous Institution "Federal Center for Regulation, Standardization and Conformity Assessment in Construction". Moscow, 2017.

16. M.V. Stepanov, G.A. Moiseenko, Construction and reconstruction 3 (83), 11-21 (2019).

17. S.A. Paschalis, A.P. Lampropoulos, O. Tsioulou, Construction and Building Materials 93, 351-366 (2018).

18. A.P. Lampropoulos, S.A. Paschalis, O. Tsioulou, Engineering Structures 106, 370-384 (2016).

19. O.V. Radaykin, L.A. Sharafutdinov, Vestnik BSTU named after V.G. Shukhov 3, 3445 (2020).

20. G. Martinola, A. Meda, G.A. Plizzari, Z. Rinaldi, Cement Concrete Compos 32, 731739 (2010). 